\title{
Capital budgeting decisions using the discounted cash flow method
}

\author{
David R. Sinclair, MD
}

Received: 17 February 2010/ Accepted: 10 March 2010/Published online: 20 March 2010

(C) Canadian Anesthesiologists' Society 2010

\section{To the Editor,}

The return on investment (ROI) method is commonly quoted in the analysis of capital investments affecting the practice of anesthesiology, such as the Anesthesia Information Management System (AIMS), handheld computer technology, and the Preoperative Evaluation Clinic. ${ }^{1-4}$ The ROI method is easy to compute and understand (Table 1). However, it measures risk rather than investment returns. The ROI method is biased against long-term projects and is based on an arbitrary, short-term cut-off date that ignores the investment's performance after the cut-off point and disregards the possibility of growing cash flows after that point. For example, one cannot disregard the cost reductions and cost savings of an AIMS resulting from reductions in anesthetic-related drug costs and increases in hospital reimbursement occurring beyond a cut-off period. Expressing these future cash flows in terms of their value today is known as the discounted cash flow (DCF) method. The DCF method is superior to the ROI method for analyzing capital investment decisions because it incorporates the time value of money. ${ }^{5}$ The DCF method estimates the value of an investment's projected future cash flows as if the cash flows were available today. It includes two main methods of discounting future cash flow. The discounted payback period rule includes the time value of money; however, like the ROI method, it is limited by an arbitrary short-term cut-off period that is biased against long-term investments. The net present value (NPV) method includes the time value of money and is a superior method for long-term projects, such as those commonly encountered in the practice of anesthesiology. The NPV method is a measure of financial value and one

D. R. Sinclair, MD ( $\square)$

University of Miami, Miami, FL, USA

e-mail: dsinclair@med.miami.edu
Table 1 Summary of formulas and calculations

The ROI formula:

Net profit / total investment $\times 100 \%$

The NPV formula:

$\left(\mathrm{OCF} /[1+\mathrm{R}]^{\mathrm{t}}\right)-\mathrm{C}$

where $(\mathrm{R})$ is the discount rate or rate of return, $(\mathrm{t})$ is the cash flow period of the investment, $(C)$ is the initial capital cost of the investment, and (OCF) is the operating cash flow

$\mathrm{ROI}=$ return on investment; NPV $=$ net present value

approach to assessing the profitability of a proposed investment. The calculation of NPV can result in one of three possible scenarios (Table 1). First, a NPV that is greater than zero adds monetary value to the organization. The capital budgeting process can be viewed as a search for investments with a positive NPV. ${ }^{5}$ From a financial standpoint, these projects should be undertaken because they add value. Second, a NPV that is less than zero would represent a loss of value to the organization if the investment were undertaken. From a financial standpoint, the investment should not be made. Third, a NPV that is equal to zero represents an indifference towards the project and the need to consider other non-monetary factors before proceeding with the investment.

The NPV should not be used to the exclusion of other variables that influence capital investment decisions simply because it is superior to the ROI method. In clinical practice, many non-economic factors take precedence over capital investment calculations, including medical evidence, quality and safety, governmental regulations, incentives, penalties, and compliance requirements. Despite the NPV of the proposed investment, the improvement in a hospital's welfare may exceed the expenditure on the project. In addition, the annual operating cash flow estimates that are based on 
operating room efficiency and payer mix can be unreliable and difficult to predict. Knowledge of the NPV method would allow clinicians to define the financial value of a capital investment decision more accurately.

Funding sources None.

Commercial or non-commercial affiliations None.

Competing interests None declared.

\section{References}

1. Fahy BG. Acute pain management efficiency improves with pointof-care handheld electronic billing system. Anesth Analg 2009; 108: $583-7$.
2. Eggr Halbeis CB, Epstein RH. The value proposition of anesthesia information management systems. Anesthesiol Clin 2008; 26: 66579.

3. Reich DL, Kahn RA, Wax D, Palvia T, Galati M, Krol M. Development of a module for point-of-care charge capture and submission using an anesthesia information management system. Anesthesiology 2006; 105: 179-86.

4. Pollard JB, Zboray AL, Mazze RI. Economic benefits attributed to opening a preoperative evaluation clinic for outpatients. Anesth Analg 1996; 83: 407-10.

5. Ross SA, Westerfield RW, Jordan BD. Fundamentals of Corporate Finance, $8^{\text {th }}$ ed. New York, NY: McGraw-Hill-Irwin; 2008: 177, 303. 